\title{
Faktor-Faktor yang Memengaruhi Moral Disengagement Siswa SMA di Provinsi Jawa Barat
}

\author{
Sarbini, Tahrir, Adang Hambali, Deden Sudirman \\ Fakultas Psikologi, UIN Sunan Gunung Djati Bandung, Indonesia \\ e-mail: tahrir@uinsgd.ac.id
}

\begin{abstract}
This research started from the phenomenon of adolescents who deliberately join with others to behaving immorally. This phenomenon illustrates moral disengagement, which is the mechanism of individual cognition to look for logical reasons that their immoral behavior can be justified logically. Previous studies found inconsistent research results about the predictors of moral disengagement. This study aims to examine the effect of concern for other, perspective taking, and internal locus of control on moral disengagement. This study used correlational quantitative method with multiple regression tests. The respondents were 482 high school and vocational high school students in West Java. The results showed that concern for others, perspective taking and internal locus of control had a significant negative effect on moral disengagement.
\end{abstract}

Keywords: concern for other, perspective taking, internal locus of control, moral disengagement

\begin{abstract}
Abstrak
Penelitian ini berawal dari penemuan fenomena remaja yang secara sengaja dan ikut-ikutan orang lain berperilaku tidak bermoral. Fenomena tersebut menggambarkan moral disengagement yaitu mekanisme kognisi individu untuk mencari alasan secara logis agar perilaku tidak bermoral meraka dapat dibenarkan secara logika. Penelitian terdahulu menemukan hasil tidak konsisten tentang variabel-variabel yang memengaruhi moral disengagement. Penelitian ini bertujuan menguji pengaruh concern for other, perspective taking, dan internal locus of control terhadap moral disengagement. Metode penelitian menggunakan kuantitatif korelasional dengan uji regresi berganda. Jumlah responden sebanyak 482 orang siswa SMA dan SMK/sederajat di Provinsi Jawa Barat. Hasil penelitian menunjukan bahwa concern for other, perspective taking dan internal locus of control berpengaruh negatif secara signifikan terhadap moral disengagement.
\end{abstract}

Kata Kunci: concern for other, perspective taking, internal locus of control, moral disengagement

\section{Pendahuluan}

Moral secara etimologi berasal dari kata mos, yang berarti kebiasaan, tata-cara, adat-istiadat dalam berperilaku. Secara linguistik moral adalah ekspresi linguistik dalam konteks moral, misalnya ungkapan benar, baik, dan harus. Reksiana (2016) menyebutkan bahwa moral adalah suatu sistem atau komponen yang saling terkait antara kesadaran dan perasaan moral ketika seseorang akan bertindak. Seseorang dikatakan bermoral jika ia sadar (mengetahui) dan merasa telah berbuat kebaikan. Selain itu moral lebih mengacu kepada suatu nilai atau sistem hidup yang berlaku di masyarakat. Ini artinya bahwa manusia yang baik adalah manusia yang dalam hidupnya senantiasa memegang teguh prinsip moral dan berperilaku sesuai dengan nilai-nilai moral yang berlaku.

Licona (dalam Reksiana, 2016) menyebutkan bahwa moral terdiri dari tiga komponen yaitu moral knowing, moral feeling, dan moral action. Moral knowing berisi tentang kesadaran moral, pengetahuan nilai-nilai moral, kemampuan 
berpikir dari sudut pandang orang lain, alasan moral, pengambilan keputusan, dan pengetahuan diri. Moral feeling berisi tentang nurani, kepercayaan diri, empati, mencintai kebenaran, kontrol diri dan kerendahan hati. Sedangkan moral action berisi tentang kompetensi, keinginan dan kebiasaan.

Individu yang telah menginternalisasi dan memedomani nilai-nilai moral, maka akan menjadikannya sebagai individu yang sangat mulia dalam hidup bermasyarakat. Nilai-nilai moral dapat digunakan untuk menentukan individu yang berbuat baik dan buruk serta individu yang berbuat salah dan benar dalam hidup bermasyarakat. Individu yang telah memedomani nilai-nilai moral maka mereka akan menahan diri dari perilaku egois dan mencegah mereka berbohong, menipu, atau mencuri dari orang lain (Ellemers dkk., 2019; Ellemers, 2017; Ellemers \& Van der Toorn, 2015).

Moral memiliki peran vital bagi individu dalam hidup bermasyarakat. Namun demikian peneliti masih mendapati banyak fenomena yang mengindikasikan individu berperilaku tidak didasarkan pada nilai-nilai moral, seperti: masih terus adanya koruptor yang tertangkap tangan oleh Komite Pemberantasan Korupsi (KPK). Berdasarkan data dari CNN online edisi 19 Desember 2018 diketahui selama tahun 2018 KPK melakukan operasi tangkap tangan sebanyak 28 kasus dan menetapkan 108 orang tersangka. Data yang diperoleh dari databoks online edisi 23 Oktober 2019 disebutkan bahwa kasus korupsi dari tahun 2014-2019 tercatat sebanyak 661 dengan 65 persen diantaranya adalah kasus penyuapan.

Harian umum Pikiran Rakyat edisi 10 September 2019 mengangkat berita bahwa trotoar di jalan protokol Kota Bandung kerap dijadikan sebagai jalan bebas hambatan bagi pengendara motor pada saat macet. Harian umum Tribunjabar edisi 12 Mei 2019 juga mengangkat berita bahwa pengendara motor sering melawan arus seperti di jalan raya Rancaekek, para pengendara beralasan untuk mempersingkat waktu tempuh karena jika melintasi jalan yang sebenarnya waktu tempuhnya terlalu lama dan jauh. Berdasarkan data pada koran Pikiran Rakyat online edisi 14 September 2019 diperoleh bahwa jumlah pelanggar kendaraan bermotor di Cimahi adalah 12.679 dan 3.276 diantaranya adalah pelajar. Demikian juga berita dari koran Pikiran Rakyat online edisi 15 September 2017 ditemukan bahwa di daerah Kuningan tercatat 2.199 dengan 788 diantaranya pelajar. Data ini menunjukkan banyaknya kasus-kasus perilaku tidak bermoral.

Berdasarkan hasil studi pendahuluan yang peneliti lakukan melalui proses observasi dan wawancara terhadap guruguru Bimbingan dan Konseling di beberapa sekolah SMA di Jawa Barat, peneliti menemukan fenomena para remaja yang melanggar aturan-aturan sekolah ataupun aturan-aturan lalu-lintas secara sengaja dengan alasan orang lain banyak yang melakukan. Masih didapat informasi dari masyarakat sekitar sekolah yang menemukan siswa-siswa SMP, SMA dan SMK atau yang sederajat, terutama di kotakota besar masih sering melakukan tawuran antar sekolah dengan alasan untuk membalas teman yang telah disakiti.

Perilaku melanggar kaidah moral lainnya adalah adanya perilaku berpacaran diluar batas-batas kewajaran, perilaku kurang menghormati guru dan orang-orang dewasa lainnya. Berdasarkan hasil wawancara tidak terstruktur terhadap para remaja yang sering melakukan pelanggaran aturan berlalu lintas dan tawuran, mereka menyebutkan bahwa mereka melakukan hal demikian karena banyak temannya yang melakukan hal sama dan tidak dikenai hukuman atau tidak kena sanksi dari masyarakat.

Kasus-kasus tersebut dalam pandangan Bandura (2016) mengambarkan perilaku moral disengagement. Bandura (2016) menyebutkan bahwa moral disengagement adalah mekanisme kognisi pada individu untuk mencari alasan secara logis agar 
perilaku tidak etis dan tidak bermoral dapat dibenarkan secara logika. Berdasarkan hasil wawancara pada para remaja didapatkan bahwa mereka melakukan pelanggaran moral karena teman-teman mereka melakukan hal yang sama dan tidak mendapat hukuman atau sanksi. Pernyataan tersebut menggambarkan bahwa mereka sedang membuat logika atau membuat alasan agar perilaku tidak bermoral tersebut bisa diterima secara logika tanpa harus mengubah perilakunya.

Menurut Clemente dkk. (2019) moral disengagement adalah suatu bentuk perilaku mementingkan diri sendiri yang melawan prinsip-prinsip kita sendiri tanpa merasa buruk. Menurut Iwai dkk. (2019) individu yang berbuat sesuai kaidah moral maka akan memperoleh respon positif dari lingkungan, demikian juga jika individu berbuat tidak sesuai kaidah moral maka akan memperoleh respon negatif. Individu yang berupaya untuk membenarkan secara logis terhadap perilaku bersalah inilah yang disebut moral disengagement (Iwai dkk., 2019). Sementara menurut Hartmann (2017) moral disengagement adalah perilaku dimana individu yang mengganggap pelanggaran sebagai perilaku yang dapat dibenarkan.

Meurut Bandura (2016) moral disengagement terjadi melalui beberapa mekanisme yaitu: 1) moral justification, melakukan pelanggaran moral untuk tujuan luhur atau tujuan mulia; 2) euphemistic labelling, penggunaan bahasa yang halus agar perilaku tidak bermoralnya terlihat baik; 3) advantageous comparison, membandingkan perilaku melanggar moral dengan perilaku pelanggaran lain yang lebih berat; 4) displacement of responsibility, melempar tanggung jawab kesalahannya kepada orang lain; 5) diffusion of responsibility, individu yang melakukan pelanggaran moral tidak mau disalahkan karena orang lain juga ikut melakukan pelanggaran; 6) disregard or distortion of consequences, individu mengabaikan begitu saja terhadap akibat dari perilaku tidak bermoralnya; 7) attribution of blame, individu selalu menyalahkan pihak lain atas perilaku tidak bermoralnya; dan 8) dehumanisation, individu berperilaku tidak manusiawi terhadap orang lain.

Mekanisme-mekanisme tersebut di atas dilakukan oleh individu semata-mata untuk membuat alasan agar perilaku tidak bermoralnya dapat diterima oleh orang lain dan dipercayai bahwa individu tersebut tidak bisa disalahkan atas pelanggaran moralnya, tanpa harus mengubah perilaku tidak bermoralnya. Namun berdasarkan penelitian Iwai dkk. (2019) menunjukkan bahwa alasan yang paling bisa dipercaya oleh individu yang melanggar moral adalah mekanisme moral justification dan displacement of responsibility.

Moral disengagement sebagai fenomena psikologis, tentu kemunculannya dapat dipengaruhi oleh banyak variabel. Seperti pendapat yang dikemukakan oleh Moore (2015) bahwa moral disengagement memiliki hubungan positif dengan ketidakjujuran, kepribadian sinis, dan external locus. Pendapat lain dari Moore (2015) bahwa moral disengagement memiliki hubungan negatif dengan perkembangan pemikiran moral, identitas moral, idealisme moral, empathetic concern, rasa bersalah, kejujuran, kerendahan hati, kesadaran, dan keramahan. Hasil penelitian tersebut menunjukkan bahwa moral disengagement dapat diminimalisir dengan meningkatkan kemampuan pemikiran moral, menanamkan identitas-identitas moral dan moral ideal, meningkatkan kemampuan concern for other, menumbuhkan rasa bersalah, kejujuran, kerendahan hati, kesadaran dan keramahan.

Penelitian Moore dkk. (2016) menemukan bahwa moral disengagemene berkorelasi positif dengan perilaku-perilaku tidak etis pada seorang karyawan di tempat kerja, seperti memberi pelayanan yang tidak memuaskan, membolos kerja, bekerja 
tidak sesuai arahan pimpinan, dan melakukan penipuan.

Bussey dkk. (2015) dalam penelitiannya juga menemukan bahwa concern for other dan perspective taking berperan sebagai variabel moderasi dalam menurunkan moral disengagement pada 1.152 remaja di Australia. Ini menunjukkan bahwa orang yang mampu merespon secara afeksi terhadap afek orang lain cenderung tidak akan melakukan moral disengagement. Penelitian Jolliffe dan Farrington (2006) di Hertfordshire London Inggris menunjukkan bahwa empati kognitif atau perspective taking berpengaruh negatif signifikan terhadap perilaku moral disengagement aspek dehumanization dalam bentuk bullying pada remaja perempuan, namun untuk empati afektif atau concern for other tidak berpengaruh signifikan pada perilaku moral disengagement aspek dehumanization berupa bullying. Demikian juga pada remaja putra empati kognitif atau perspective taking dan afektif atau concern for other tidak berpengaruh negatif signifikan terhadap perilaku moral disengagement aspek dehumanization berupa bullying.

Penelitian Caravita dkk. (2009) di Italia Utara terhadap anak usia 6-10 tahun menemukan bahwa empati kognitif dan empati afektif berpengaruh negatif tidak langsung melalui persepsi popularitas terhadap moral disengagement bullying. Sementara pada remaja usia 11-14 tahun ditemukan bahwa empati afektif berpengaruh negatif secara langsung terhadap moral disengagement bullying walaupun signifikan, namun empati kognitif berpengaruh positif secara langsung dan signifikan terhadap moral disengagement bullying. Hasil penelitian Cohen dkk. (2015) menemukan bahwa empati yang tinggi menurunkan kecenderungan individu untuk berperilaku agresi (moral disengagement aspek dehumanization). Demikian juga hasil penelitian Wang dkk. (2017) terhadap 357 remaja nakal usia 14-26 tahun ditemukan bahwa empati berhubungan negatif dengan moral disengagement dan empati juga berhubungan negatif dengan bullying.

Moral disengagement selain dipengaruhi oleh concern for other dan perspective taking juga dipengaruhi oleh locus of control. Menurut Moore (2015) moral disengagement berkorelasi positif dengan external locus of control. Artinya bahwa external locus of control menjadi penyebab yang dapat meningkatkan terjadinya perilaku moral disengagement. Menurut Weimer dkk. (2017) bahwa kemampuan untuk melakukan penilaian moral sangat berkaitan erat dengan locus of control individu. Tahrir dkk. (2020) dalam penelitiannya terhadap mahasiswa yang tinggal di pesantren menemukan bahwa mahasiswa yang memiliki internal locus of control tinggi mampu untuk mengontrol perilakunya agar tidak melanggar nilai-nilai moral yang telah disepakati bersama di pesantren.

Aprilia dan Solicha (2013) dalam penelitiannya menemukan bahwa jenis kelamin, external locus chance, external locus context, dan internal locus effort memengaruhi secara signifikan terhadap moral disengagement. Hasil penelitian ini menunjukkan bahwa tingginya external locus chance, external locus context dapat memicu tingginya moral disengagement remaja. Sedangkan tingginya internal locus effort remaja dapat menjadi penghambat munculnya moral disengagement. Namun concern for other, perspective taking, dan internal locus ability tidak memengaruhi secara signifikan terhadap moral disengagement.

Berdasarkan hasil review yang peneliti lakukan terhadap penelitian-penelitian sebelumnya tentang variabel-variabel yang memengaruhi moral disengagement, peneliti menemukan adanya hasil yang tidak konsisten atau kontradiksi antara satu penelitian dengan penelitian yang lain. Penelitian Moore (2015) menyebutkan bahwa concern for other berkorelasi negatif 
dengan moral disengangement. Penelitian Kokkinos dan Kipritsi (2017) juga menemukan empati kognitif (perspective taking) dan empati afektif (concern for other) berpengaruh negatif signifikan terhadap moral disengagement.

Penelitian Jolliffe dan Farrington (2006) juga menunjukkan bahwa empati kognitif atau perspective taking berpengaruh negatif signifikan terhadap moral disengagement aspek dehumanization bullying. Caravita dkk. (2009) dalam penelitiannya juga menemukan empati kognitif dan empati afektif berpengaruh negatif tidak langsung melalui persepsi popularitas terhadap moral disengagement bullying. Selanjutnya penelitian Wang dkk. (2017) menemukan empati berhubungan negatif dengan moral disengagement dan bullying.

Namun Aprilia dan Solicha (2013) dalam penelitiannya menemukan bahwa concern for other, perspective taking, dan internal locus berpengaruh terhadap moral disengagement namun tidak signifikan. Penelitian lain dari Caravita dkk. (2009) juga menemukan bahwa empati kognitif atau perspective taking dan afektif atau concern for other tidak berpengaruh secara signifikan terhadap perilaku dehumanization bullying. Demikian juga hasil penelitian Jolliffe dan Farrington (2006) menunjukkan bahwa empati afektif tidak berpengaruh terhadap moral disengagement bullying secara signifikan.

Peneliti juga menemukan kontradiksi hasil penelitian yang menyatakan bahwa moral disengagement dipengaruhi oleh locus of control. Menurut Moore (2015) external locus of control berkorelasi positif dengan moral disengagement. Demikian juga hasil penelitian Tsai dkk. (2014) locus of control berpengaruh terhadap moral disengagement secara signifikan. Penelitian Detert dkk. (2008) juga menemukan individu dengan external locus of control cenderung akan menyalahkan faktor eksternal dan mengaburkan tanggung jawab atas perilaku tidak etisnya.
Namun penelitian lain dari Detert dkk. (2008) menemukan fakta lain bahwa internal locus of control dan external locus of control power tidak berkorelasi signifikan dengan moral disengagement. Demikian juga penelitian Aprilia dan Solicha (2013) menemukan bahwa internal locus ability merupakan variabel yang tidak signifikan pengaruhnya terhadap moral disengagement.

Berdasarkan kontradiksi-kontradiksi hasil penelitian sebelumnya terkait dengan variabel-variabel yang memengaruhi moral disengagement, maka peneliti terdorong untuk melakukan penelitian guna mengetahui variabel-variabel mana yang benar-benar memengaruhi moral disengagement. Peneliti ingin membuktikan ulang variabel mana diantara perspective taking, concern for other, internal locus of control yang betul-betul memengaruhi moral disengagement. Penelitian ini juga didasarkan pada fenomena yang peneliti temukan pada siswa-siswa SMA dan SMK di kota-kota besar seperti kota-kota di Jawa Barat. Oleh karena itu penting untuk dilakukan kembali penelitian tentang empathy concern for other, empathy perspective taking, internal locus of control dan moral disengagement.

\section{Metode Penelitian}

Pendekatan yang digunakan dalam penelitian ini adalah pendekatan kuantitatif dengan rancangan korelasional. Responden dalam penelitian ini adalah siswa SMA dan SMK atau yang sederajat di Jawa Barat dengan jumlah responden 482 orang, terdiri dari 215 laki-laki dan 267 perempuan yang rata-rata berusia 16.2 tahun. Proses pengambilan sampel menggunakan multistage random sampling berdasarkan pada area atau dearah sekolah. Berdasarkan hasil pengambilan random maka diperoleh sekolah Madrasah Aliyah Swasta Al Istiqomah Sukabumi, Sekolah Menengah Kejuruan Swasta Mihadunal Ula Sukabumi, Madrasah Aliyah Negeri 2 Garut, Sekolah Menengah Atas Negeri 1 
Karawang, dan Sekolah Menengah Atas Negeri 1 Kerangkeng Indramayu.

Alat ukur menggunakan Interpersonal Relationship Inventory (IRI) yang dibuat oleh Davis dan direvisi oleh Kaeton (2017) untuk mengukur variabel concern for other dan perspective taking terdiri dari 26 item. Peneliti melakukan modifikasi untuk menyesuaikan dengan latar belakang budaya responden serta menambahkan jumlah item sehingga menjadi 28 item. Hasil analisis item menunjukkan bahwa dari 28 item tersebut, terdapat 26 item yang memiliki daya beda berkisar antara .443 sampai dengan .772, sedangkan 2 item memiliki daya beda di bawah .3 (item 23 dan 26). Indeks validitas sebesar .64 dan reliabilitas sebesar .95 untuk variabel concern for other. Sedangkan variabel perspective taking memiliki indeks validitas sebesar .60 dan indeks reliabilitas sebesar .93 .

Variabel internal locus of control menggunakan alat ukur Academic Locus of Control Scale for College Students (ALCSCS) dari Curtis dan Trice (2013) terdiri dari 29 item. Terdapat 25 item yang memiliki daya beda berkisar dari .625 sampai dengan .817, sedangkan 4 item (item 2, 7, 14, 22) memiliki daya beda di bawah .3. Alat ukur ini memiliki indeks validitas sebesar .68 serta indeks reliabilitas sebesar 98.

Variabel moral disengagement menggunakan alat ukur mechanism of moral disengagement scale (MMDS-S) dari Rubio-Garay dkk. (2017) yang telah dimodifikasi, dengan jumlah item semula sebanyak 32 item menjadi 34 item. Terdapat 27 item yang memiliki daya beda berkisar dari .366 sampai dengan .872, sedangkan sisanya sebanyak 7 item memiliki daya beda di bawah .3. diperoleh indeks validitas sebesar .70 serta reliabilitas sebesar .99. Ketiga alat ukur tersebut merupakan alat ukur yang sesuai dengan teori yang digunakan dalam penelitian ini. Selain itu alat ukur tersebut telah diujicobakan pada responden dengan karakterisirik yang hampir sama yaitu remaja akhir. Adapun metode untuk menganalisis data hasil penelitian menggunakan analisis regresi linear berganda.

\section{Hasil Penelitian dan Pembahasan}

Berdasarkan pengujian statistik diperoleh hasil sebagaimana disajikan pada tabel 1. Diketahui bahwa nilai $\mathrm{R}$ sebesar .380 , ini menunjukkan adanya hubungan negatif antara concern for other, perspective taking dan internal locus of control dengan moral disengagement pada siswa SMA dan SMK/sederajat di Provinsi Jawa Barat. Selanjutnya untuk melihat besaran nilai determinasi atau kontribusi pengaruh concern for other, perspective taking dan internal locus of control terhadap moral disengagement, maka dapat dilihat dari nilai R Square sebesar .144. Ini artinya konstribusi ketiga variabel tersebut dalam menurunkan perilaku moral disengagement adalah sebesar $14.4 \%$ dan $86 \%$ lainnya dipengaruhi oleh faktor-faktor lain di luar variabel-variabel yang diteliti.

Berdasarkan pada tabel 2 diketahui bahwa nilai $F_{\text {hitung: }} 26.896>F_{\text {tabel }}: 3.04$ dan palue: $.000<\alpha$ : .05 . Dapat disimpulkan bahwa concern for other, perspective taking, dan internal locus of control secara simultan berpengaruh signifikan terhadap moral disengagement.

Tabel 1

Hasil Uji Korelasi

\begin{tabular}{lcccc}
\hline Model & $R$ & $R$ Square & $\begin{array}{c}\text { Adjusted } R \\
\text { Square }\end{array}$ & $\begin{array}{c}\text { Std. Error } \\
\text { of the } \\
\text { Estimate }\end{array}$ \\
\hline 1 & $-.380^{\mathrm{a}}$ & .144 & .139 & 9.19074 \\
\hline
\end{tabular}

a. Predictors: (Constant), CFO, PT, ILC 
Tabel 2

Hasil Uji Anova

\begin{tabular}{lrrrrr}
\hline & Sum of & \multicolumn{4}{c}{ Mean } \\
Model & Squares & Df & Square & \multicolumn{1}{c}{$F$} & Sig. \\
\hline 1 Regression & 6815.7 & 3 & 2271.9 & 26.9 & $.000^{\mathrm{b}}$ \\
$\quad$ Residual & 40460.9 & 479 & 84.4 & & \\
$\quad$ Total & 47276.7 & 482 & & & \\
\hline
\end{tabular}

a. Dependent Variable: MD

b. Predictors: (Constant), CFO, PT, ILC

Tabel 3

Hasil Uji Parsial

Unstandardized Standardized Coefficients Coefficients

\begin{tabular}{cccccc} 
Model & $B$ & Error & Beta & $T$ & Sig. \\
\hline Constant & 6.01 & 5.39 & & 1.11 & .265 \\
PT & -.68 & .21 & -.15 & -3.21 & .001 \\
CFO & -.65 & .22 & -.13 & -2.89 & .004 \\
ILC & -.42 & .08 & -.23 & -4.76 & .000
\end{tabular}

a. Dependent Variable: Moral Disengagement

Berdasarkan hasil uji parsial sebagaimana disajikan pada tabel 3, maka diketahui bahwa perspective taking berpengaruh negatif dan signifikan terhadap moral disengagement karena nilai $t_{\text {hitung: }}$-3.214 $>t_{\text {tabel }}: 1.97$ dengan $p_{\text {value }}: .001$ $<\alpha$ : .05. Ini artinya bahwa semakin tinggi skor perspective taking maka semakin rendah moral disengagement remaja. Concern for other juga berpengaruh negatif signifikan terhadap moral disengagement

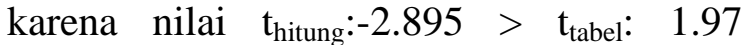
dengan $p_{\text {value }}: .004<\alpha$ : .05. Ini artinya bahwa semakin tinggi skor concern for other maka semakin rendah moral disengagement remaja. Demikian juga internal locus of control berpengaruh negatif signifikan terhadap moral disengagement karena nilai $\mathrm{t}_{\text {hitung }}:-4.762>$ $t_{\text {tabel }}: 1.97$ dengan $p_{\text {value }}: .000<\alpha: .05$. Ini artinya bahwa semakin tinggi skor internal locus of control maka semakin rendah moral disengagement remaja.

Penelitian ini membuktikan bahwa concern for other adalah salah satu variabel penting yang dapat menurunkan moral disengagement remaja. Menurut Moore (2015) moral disengagement berhubungan negatif dengan perkembangan moral kognitif, identitas moral, idealisme moral, empathetic concern, rasa bersalah, kejujuran, dan kesadaran diri. Menurut Zickfeld dkk. (2017) individu yang memiliki concern for other tinggi adalah individu yang memiliki kesatuan cinta dengan orang lain, kesatuan perasaan dengan orang lain, keluarga, kelompok dan bahkan dengan binatang.

Secara numerik pengaruh dari ketiga variabel dalam penelitian ini adalah kecil karena hanya $14.4 \%$. Namun penelitian lain yang dilakukan oleh Haddock dan Jimerson (2017) juga menemukan bahwa variabel perspective taking memiliki pengaruh yang kecil terhadap moral disengagement yaitu hanya sebesar $2.2 \%$. Sedangkan variabel concern for other hanya memiliki pengaruh sebesar $3.6 \%$. Demikian halnya hasil penelitian Detert dkk. (2008) bahwa internal locus of control juga memiliki pengaruh yang kecil terhadap moral disengagement yaitu sebesar $.16 \%$. Meskipun hasil penelitian ini pengaruhnya kecil, akan tetapi karena uji hipotesis menunjukkan bahwa $\mathrm{H}_{1}$ diterima secara signifikan maka menurut peneliti variabel concern for other, perspective taking, dan internal locus of control sangat penting dalam upaya menurunkan moral disengagement remaja di Jawa Barat.

Menurut Haidt dan Kesebir (seperti dikutip oleh Kish-Gephart dkk., 2014) individu dengan kemampuan concern for other yang tinggi senantiasa peduli dan mendukung terhadap kelangsungan hidup bermasyarakat. Kemampuan-kemampuan tersebutlah yang menjadikan individu dengan concern for other yang tinggi benar-benar dapat tetap menjaga nilai-nilai yang telah disepakati secara bersama dalam masyarakatnya.

Penelitian ini juga membuktikan bahwa tingginya perspective taking pada individu dapat menurunkan moral disengagement. Menurut Erle dan Topolinski (2017) perspective taking adalah kognisi sosial yang dapat membantu individu memahami orang lain melalui penciptaan perasaan kedekatan, simpati, 
dan pengambilalihan pikiran orang lain. Selain itu, perspective taking adalah kemampuan individu yang bersifat nonegosentrik, artinya kemampuan ini yang tidak berorientasi pada kepentingan sendiri, tapi kemampuan yang lebih berfokus pada kepentingan orang lain (Erle \& Topolinski, 2017). Kemampuan inilah yang menjadi pendorong individu untuk mengurangi perilaku tidak bermoral atau bahkan menghilangkan perilaku tidak bermoralnya agar tidak merugikan orang lain.

Penelitian ini juga membuktikan bahwa internal locus of control pada individu dapat menurunkan moral disengagement. Manusia sebagai makhluk sosial tentu tidak bisa lepas dari orang lain dalam kehidupannya. Pada saat menjalani kehidupan sosialnya manusia sangat membutuhkan aturan-aturan, nilai-nilai dan etika yang menjadi pengikat dan aturan yang disepakati secara bersama. Pada dasarnya setiap manusia memiliki nilainilai dan etika yang bisa digunakan sebagai dasar untuk berperilaku dalam kehidupan bermasyarakat. Namun tidak bisa dipungkiri banyak manusia yang memutuskan untuk berperilaku tidak berlandaskaan pada nilai-nilai dan etika yang disepakati bersama di masyarakat. Salah satu atribut psikologis yang diduga dapat menjadi penyebab manusia berperilaku tidak bermoral adalah locus of control.

Sesuai dengan penelitian Wanodya dan Aniputra (2017) menunjukkan bahwa para pemandu karaoke yang berprofesi sebagai pekerja seks komersial ternyata perilaku-perilaku mereka banyak diakibatkan oleh rendahnya internal locus of control yang mereka miliki. Demikian juga hasil penelitian Antelo dan Gordillo (2019) menunjukkan bahwa locus of behavior dan locus of outcomes dapat mengendalikan diri individu untuk tidak melakukan moral disengagement humanization dan cyberbullying. Walapun demikian individu yang memiliki internal locus of control tidak otomatis akan menjamin dirinya berperilaku etis, namun kemampuan tersebut akan mempermudah individu untuk melawan arus jika memiliki keinginan untuk mengubah keadaan dirinya menjadi positif. Dalam studi mereka tentang locus of control dan moral disengagement, Detert dkk. (2008) menemukan bahwa orang dengan external locus of control cenderung menyalahkan faktor eksternal dan menyebarkan tanggung jawab kepada pihak lain. Dengan penelitian ini Detert dkk. (2008) berkesimpulan bahwa individu dengan external locus of control lebih mungkin melakukan moral disengagement yang lebih tinggi daripada individu dengan internal locus of control.

\section{Simpulan}

Berdasarkan hasil penelitian diketahui bahwa concern for other, perspective taking dan internal locus of control adalah variabel yang memiliki peran signifikan dalam menurunkan perilaku moral disengagement pada siswa SMA dan SMK sederajat di Provinsi Jawa Barat.

\section{Daftar Pustaka}

Antelo, I. F., \& Gordillo, I. C. (2019). Moral disengagement as an explanatory Factor of the polyivictimization of bullying and cyberbullying. International Journal of Environmental Research and Public Health, 16(13),

2414. https://doi.org/10.3390/ijerph161 32414

Aprilia, Z., \& Solicha, S. (2013). Faktorfaktor yang mempengaruhi moral disengagement remaja. Tazkiya Journal of Psychology, 1(1), 1-17.

Baihaki, H. (2019, Mei 12). Hanya garagara ini, banyak pengendara motor melawan arus di jalan raya BandungGarut. Tribun Jabar. https://jabar.tribunnews.com/2019/05/1 2/hanya-gara-gara-ini-banyak- 
pengendara-motor-melawan-arus-dijalan-raya-bandung-garut

Bandura, A. (2016). Moral disengagement: How people do harm and live with themselves $1^{\text {st }}$ ed. 2016 edition. Worth Publishers.

Bussey, K., Quinn, C., \& Dobson, J. (2015). The moderating role of empathic concern and perspective taking on the relationship between moral disengagement and aggression. Merrill-Palmer Quarterly, 61(1), 1029. Project.MUSE muse.jhu.edu/article 1577565.

Caravita, S. C. S., Di Blasio, P., \& Salmivalli, C. (2009). Unique and interactive effects of empathy and social status on involvement in bullying. Social Development, 18(1), 140-

163. https://doi.org/10.1111/j.14679507.2008.00465.x.

Clemente, M., Espinosa, P., \& Padilla, D. (2019) Moral disengagement and willingness to behave unethically against ex-partner in a child custody dispute. PLoS ONE, 14(3): e0213662. https://doi.org/10.1371/journal.pone.02 13662

Cohen, S., Schulz, M. S., Liu, S. R., Halassa, M., \& Waldinger, R. J. (2015). Empathic accuracy and aggression in couples: Individual and dyadic links. Journal of Marriage and Family, 77(3), 697-711. https://doi.org/10.1111/jomf. 12184

Curtis, N. A., \& Trice, A. D. (2013). A revision of the academic locus of control scale for college students. Perceptual \& Motor Skills, 116(3), 817-829.

https://doi.org/10.2466/08.03.PMS.116 .3.817-829

Detert, J. R., Trevino, L. K., \& Sweitzer, V. L. (2008). Moral disengagement in ethical decision making: A study of antecedents and outcomes. Journal of Applied Psychology, 93(2), 374-391.
Ellemers, N., \& Van der Toorn, J. (2015). Groups as moral anchors. Current Opinion in Behavioral Sciences, 6, 189-194.

Ellemers, N. (2017). Morality and the regulation of social behavior: Groups as moral anchors. Routledge.

Ellemers, N., Toorn, J. V. D., Paunov, Y., \& Leeuwen, T. V. (2019). The psychology of morality: A review and analysis of empirical studies published from 1940 through 2017. Personality and Social Psychology Review, 23(4), 332-366.

Erle, T. M., \& Topolinski, S., (2017). The grounded nature of psychological perspective-taking. Journal of Personality and Social Psychology, 112(5), 683-695. https://doi.org/10.1037/pspa0000081

Haddock, A. D., \& Jimerson, S. R. (2017). An examination of differences in moral disengagement and empathy among bullying participant groups. Journal of Relationships Research, 8, Article e15. https://doi.org/10.1017/jrr.2017.15

Hartmann, T. (2017). The moral disengagement in violent videogames model. The International Journal of Computer Game Research, 17(2).

Iwai, T., Carvalho, J. V. F., \& Lalli, V. M. (2019). Explaining transgressions with moral disengagement strategies and their effects on trust repair. Brazilian Administration, 15(4), 1-23. http://dx.doi.org/10.1590/18077692 bar2018180016

Jolliffe, D., \& Farrington, D. P. (2006). Examining the relationship between low empathy and bullying. Aggressive Behavior, 32, 540-550.

Kaeton, S. A. (2017). Profile 28 Interpersonal Reactivity Index (IRI) (Davis, 1980). Dalam D.L. Worthington \& G. D. Bodie (Eds.), Sourcebook of Listening Methodology \& Measures, First Edition. John Wiley $\& \quad$ Sons, Inc. 
https://doi.org/10.1002/978111910299 1.ch34

Kish-Gephart, J., Detert, J., Trevino, L. K., Beker, V., \& Martin, S. (2014). Situational moral disengagement: Can the effects of self-interest be mitigated? Journal of Bussiness Ethics, 125(2), 267-285.

https://doi.org/10.1007/s10551-0131909-6.

Kokkinos, C. M., \& Kipritsi, E. (2017). Bullying, moral disengagement and empathy: Exploring the links among early adolescents. Educational Psychology: An International Journal of Experimental Educational Psychology, 38(4), 535-552. https://doi.org/10.1080/01443410.2017 .1363376

Kusnandar, V. B. (2019, Oktober 23). 65 persen tindak pidana korupsi yang ditangani KPK merupakan kasus penyuapan.

Databoks. https://databoks.katadata.co.id/datapub lish/2019/10/23/65-persen-tindakpidana-korupsi-yang-ditangani-kpkmerupakan-kasus-penyuapan

Moore, C. (2015). Moral disengagement. Current Opinion in Psychology, 6, 199-204.

https://doi.org/10.1016/j.copsyc.2015.0 7.018

Moore, C., Detert, J. R., Treviño, L. K., Baker, V. L., \& Mayer, D. M. (2016). "Why employees do bad things: Moral disengagement and unethical organizational behavior": Corrigendum. Personnel Psychology, 69(1),

307. https://doi.org/10.1111/peps.1213 7

Novelino, A. (2018, Desember 28). KPK tangkap tangan pejabat kementerian PUPR. CNN Indonesia. https:/www.cnnindonesia.com > nasional > 20181228192854-12-357148

Reksiana. (2018). Kerancuan istilah karakter, akhlak, moral dan etika. Thaqãfiyyãt: Jurnal Bahasa,
Peradaban dan Informasi Islam, 19(1), 1-30.

Rubio-Garay, F., Amor, P. J., \& Carrasco, M. A. (2017). Dimensionality and psychometric properties of the Spanish version of the mechanisms of moral disengagement scale (MMDS-S). Revista de Psicopatología y Psicología Clínica, 22(1), 43-54. https://doi.org/10.5944/rppc.vol.22.nu m.1.2017.16014

Suryadi, K. (2019, September 10). Berebut trotoar. Pikiran Rakyat. https://www.pikiranrakyat.com/kolom/pr01318920/berebut-trotoar

Tahrir, Nurdin, F. S., \& Damayanti, I. R. (2020). The role of critical thinking as a mediator variable in the effect of internal locus of control on moral disengagement. International Journal of Instruction, 13(1).

Tsai, J., Wang, C., \& Lo, H. (2014). Locus of control, moral disengagement in sport, and rule transgression of athletes. Social Behavior and Personality: An International Journal, 42, 5968. https://doi.org/10.2224/sbp.2014.42 .1 .59

Wang, X., Lei, L., Yang, J., Gao, L., \& Zhao, F. (2017). Moral disengagement as mediator and moderator of the relation between empathy and aggression among Chinese male juvenile delinquents. Child Psychiatry and Human Development, 48(2), 316326. https://doi.org/10.1007/s10578016-0643-6

Wanodya, R. G. A., \& Aniputra, B. (2017). Moral disengagement pada pemandu karaoke yang berprofesi sebagai pekerja seks komersial terselubung. Jurnal Psikologi Kepribadian dan Sosial, 6, 49-62.

Weimer, K., Ahlström, R., Lisspers, J., \& Lipsanen, J. (2017). Values, attitudes, moral judgment competence, locus of control and sense of coherence as 
Faktor-Faktor yang Memengaruhi Moral Disengagement Siswa SMA di Provinsi Jawa Barat (Sarbini, Tahrir, Adang Hambali, Deden Sudirman)

determinants of pro-environmental behaviors and behavioral intentions. Journal of Multidisciplinary Engineering Science and Technology (JMEST), 4(5), 2568-2583.

Zickfeld, J. H., Schubert, T. W., Seibt, B., \& Fiske, A. P. (2017). Empathic concern is part of a more general communal emotion. Frontiers in Psychology, 8, Article 723. https://doi.org/10.3389/fpsyg.2017.007 23 
Psympathic, Jurnal Ilmiah Psikologi Desember 2019, Vol. 6, No. 2, Hal. : 145-156 